\title{
Proteomic Profiling of Cerebrospinal Fluid by 8-Plex iTRAQ Reveals Potential Biomarker Candidates of Alzheimer's Disease
}

\author{
N. Guerreiro • B. Gomez-Mancilla • B. Williamson • \\ M. Minkoff $\cdot$ S. Guertin
}

Published online: 12 May 2009

(C) Humana Press 2009

\begin{abstract}
Introduction Alzheimer's disease (AD) poses specific challenges for drug development. It has a slow and variable clinical course, an insidious onset, and symptom expression is only observed when a significant proportion of neurons are already lost.

Discussion Determinants of clinical course, such as molecular biomarkers, are urgently needed for early detection and diagnosis, or for prognosis and monitoring disease-modifying therapies in stratified patient populations. Due to its proximity to the brain and clinical availability, cerebrospinal fluid (CSF) is likely to have the highest yield of biomarker potential for neurodegenerative diseases. In this study, we examined the feasibility of using of an 8-plex isobaric tagging approach, coupled to two-dimensional liquid chromatography and tandem mass spectrometry using the matrix-assisted laser desorption/ionization time-of-flight/time-of-flight platform, for the discovery of potential biomarker candidates in CSF. Comparative analysis identified a number of statistically significant differences in the level of proteins when comparing $\mathrm{AD}$ to nondemented controls. Although the study is statistically underpowered to represent the disease population, the regulation of proteins with involvement in processes such as neuronal loss, synaptic dysfunction, neuroinflammation, and tissue degeneration and remodeling reflects the ability of our method in providing biologically meaningful CSF
\end{abstract}

N. Guerreiro $(\bowtie) \cdot$ B. Gomez-Mancilla

BioMarker Development, Translational Sciences, Novartis,

Klybeckstasse,

4002 Basel, Switzerland

e-mail: nelson.guerreiro@novartis.com

B. Williamson $\cdot$ M. Minkoff $\cdot$ S. Guertin

Applied Biosystems,

Framingham, MA, USA biomarkers as candidates for larger scale biomarker verification and validation studies.

Keywords Liquid chromatography · Neurodegeneration · Proteome $\cdot$ Neuroplasticity $\cdot$ Inflammation

$\begin{array}{ll}\text { Abbreviations } \\ \text { AD } & \text { Alzheimer's disease } \\ \text { CSF } & \text { Cerebrospinal fluid } \\ \text { CNS } & \text { Central nervous system } \\ \text { iTRAQ } & \begin{array}{l}\text { Isobaric tags for relative and absolute } \\ \text { quantitation }\end{array} \\ \text { LC } & \text { Liquid chromatography } \\ \text { MALDI } & \text { Matrix-assisted laser desorption ionization } \\ \text { TOF } & \text { Time of flight } \\ \text { MCI } & \text { Mild cognitive impairment } \\ \text { MS } & \text { Mass spectrometry } \\ \text { NDC } & \text { Nondemented controls } \\ \text { PCA } & \text { Principle component analysis } \\ \text { SCX } & \text { Strong cation exchange } \\ \text { TEAB } & \text { Triethylammonium bicarbonate }\end{array}$

\section{Introduction}

Alzheimer's disease (AD) is an age-related progressive neurodegenerative disorder characterized clinically by cognitive decline and dementia. AD brains are marked by amyloid plaques and neurofibrillary tangles, synaptic and neuronal cell loss, a prominent activation of glial cells, and innate immune responses [1]. Except for the rare inherited early onset forms of $\mathrm{AD}$, the etiology of the more common sporadic form is still poorly understood. Currently used clinical diagnostic evaluations are insufficient and highly 
subjective, and there is considerable heterogeneity in their cognitive, behavioral, and functional measures [2]. Although the diagnostic accuracy, verified by pathological examination, may reach $85-90 \%$, AD cannot be diagnosed clinically until after substantial irreversible tissue atrophy has occurred.

The treatment of AD has turned to modify the course of the pathological process. Several immunotherapies are presently under investigation for efficacy in reducing betaamyloid in the brain of patients with mild moderately advanced disease. Unfortunately, development of diseasemodifying therapy for $\mathrm{AD}$ is still hampered by late diagnosis and by the lack of definitive measurable variables which discriminate $\mathrm{AD}$ from vascular dementia, frontotemporal dementia, or dementia with Lewy bodies early in the disease state. It is commonly agreed that disease-modifying therapy is most effective when administered in earliest stages of neurodegenerative disorder before much tissue has been irretrievably lost [2]. There is sufficient evidence that characteristic changes in biochemistry are present long before the onset of clinical symptoms and that many patients with mild cognitive impairment (MCI) already have significant neuropathology in the early stage of AD. Especially promising is the measurement of antecedent molecular biomarkers in cerebrospinal fluid (CSF) that will identify those presymptomatic individuals with MCI who will convert to AD. Such molecular biomarkers which also reflect the neuropathology and are modifiable by treatment would provide invaluable support for disease modification claims [3-6].

Proteomic approaches are now widely used in the investigation of neurodegenerative diseases and, in particular, as a nonbiased quantification approach for the detection of differences in global patterns of proteins and peptides between healthy and diseased individuals [6-13]. One of the driving forces of proteomics in drug development is the discovery of biomarker candidates of potential clinical relevance in the periphery [14-16]. Due to its proximity to the brain and clinical availability, CSF is a unique medium by which to detect biochemical changes in the central nervous system (CNS). CSF continuously circulates through cavities in the brain, spinal cord, and in the subarachnoid space, carrying proteins of neural cell origin that play critical roles in many physiological processes. As such, any variation in protein composition or abundance relative to normal CSF may potentially reflect pathological processes in the surrounding brain tissue and other parts of the CNS [3, 17].

New advances on quantitative proteomic analysis and multidimensional protein identification technologies have greatly enhanced the capability of proteomic methods to study the expressions, modifications, and functions of protein biomarkers in complex mixtures including CSF
[18]. One key development has been the advent of multiplexing technologies such as the isobaric tags for relative and/or absolute quantification (iTRAQ) of complex protein mixtures $[19,20]$. iTRAQ is a chemical labeling approach that incorporates stable isotopes into an $\mathrm{N}$-hydroxysuccinimide ester derivative amine tagging agent that, when combined with mass spectrometry, allows comparative quantitative multiplexing analysis. Each protein sample is proteolytically digested with trypsin; tryptic fragments are labeled with one of the isobaric tags at $\mathrm{N}$ terminus and lysine residues and mixed with the other different iTRAQ-labeled samples. The samples are analyzed by tandem mass spectrometry (MS/MS), and proteins quantified by the relative intensities of the iTRAQ reporter ions in the MS/MS spectra, while simultaneously obtaining a peptide sequence. ITRAQ is ideally suited for biomarker discovery as it provides both quantitation and multiplexing in one analysis. Recently, an 8-plex version of the iTRAQ reagents was shown to be successful in profiling the protein content of CSF collected from a longitudinal study of individuals undergoing intravenous Ig treatment for $\mathrm{AD}$ [21] and from a gender comparative study [22]. In this current study, a two-dimensional liquid chromatography and tandem mass spectrometry using the matrix-assisted laser desorption/ ionization time-of-flight/time-of-flight (2DLC-MALDI-MS/ MS) approach incorporating 8-plex iTRAQ labeling is described for its potential use as biomarker discovery platform. We described the utility of the platform as a tool for profiling the CSF proteome to allow the identification of protein differences between nondemented controls (NDC) and individuals diagnosed with probable $\mathrm{AD}$ that can be proposed as potentially biomarker candidates for further verification and validation studies.

\section{Experimental Procedures}

\section{Cerebrospinal Fluid Samples}

The study was done according to the guidelines of the local ethical committee, and for each CSF sample, a written informed consent was obtained from the patients or patients' next of kin. The patients underwent a thorough clinical examination, including medical and family history, neurological, psychiatric examinations, routine laboratory testing, neuropsychological testing, and magnetic resonance imaging of the brain. Clinical diagnoses were made according to established international criteria. Eight patients diagnosed with "probable $\mathrm{AD}$ " and eight age-matched control subjects (ranging from 70 to 80 years) neurologically tested as cognitively normal were recruited. CSF samples were obtained by lumbar puncture as part of a routine clinical procedure. CSF samples with hematic appearance or with a high red blood cell count $(>10 \mathrm{RBC} / \mu \mathrm{L})$ were 
excluded from the present study. The samples were centrifuged at 2,000 $\times g$ for $10 \mathrm{~min}$ to remove cells and other insoluble material. Supernatants were frozen in aliquots and stored at $-80^{\circ} \mathrm{C}$ until analysis.

\section{Reagents and Chemicals}

The chemical reagents ethanol, isopropanol, trifluoroacetic acid (TFA), triethylammonium bicarbonate (TEAB), $\alpha$-cyano-4hydoxycinnamic acid, and tris-[2-carboxethyl]phosphine were obtained from Sigma Corporation (St. Louis, MO, USA). High-performance liquid chromatography grade acetonitrile (ACN) and ultrapure water were obtained from J. T. Baker (Deventer, Holland). All iTRAQ reagents and buffers were obtained from Applied Biosystems (Foster City, CA, USA).

\section{Depletion}

The general protocol recommended by Applied Biosystems Inc. (ABI, Foster City, CA, USA) was followed for depletion. A 1-mL sample volume of CSF from each patient was diluted 1:5 in phosphate buffered saline and centrifuged for $10 \mathrm{~min}$ at $2,000 \mathrm{rpm}$ at $4^{\circ} \mathrm{C}$. The supernatant was filtered with $0.22 \mu \mathrm{m}$ membrane and the filtrate was loaded onto a Vision Workstation. Each sample was passed over a 2-mL antihuman serum albumin (HSA) column and a $0.2-\mathrm{mL}$ Protein $\mathrm{G}$ column set in tandem (ABI), for the removal of HSA and IgG, respectively, from CSF according to the manufacturer's instructions. The unbound material also passed through a POROS R1, 50- $\mu \mathrm{m}$ particle size, reverse phase column (ABI). The reverse phase column was washed with $2 \% v / v$ ACN and $0.1 \% v / v$ TFA to desalt the sample and then eluted in $50 \% \mathrm{ACN}$ and $0.1 \%$ TFA. Each fraction was then dried in vacuo. Material bound to the depletion columns was eluted in $12 \mathrm{mM} \mathrm{HCl}$. Total protein content was determined using a bicinchoninic acid assay (Pierce, Rockford, IL, USA).

\section{Experimental Design}

The samples were split by gender into two 8-plex experiments. Here, a reference sample pooled from an aliquot of each sample (male and female) is allocated to each 8-plex experiment using the same labeling tag, and the patient samples are allocated to the remaining tags. For each 8-plex experiment, equivalent amounts of protein from each patient sample and the global standard was reduced, alkylated, digested, and labeled with one of the isobaric reagents.

\section{Trypsin Digestion}

Protein denaturation, reduction, and digestion were performed following the protocol recommended by ABI.
Briefly, $20 \mu \mathrm{L}$ of $0.5 \mathrm{M}$ TEAB pH $8.5,1 \mu \mathrm{L}$ of denaturant ( $2 \% w / v$ sodium dodecyl sulfate), and $2 \mu \mathrm{L}$ of reducing agent (50 $\mathrm{mM}$ tris-[2-carboxethyl]phosphine) were added to each tube containing $50 \mu \mathrm{g}$ of protein of depleted sample and incubated for $1 \mathrm{~h}$ at $60^{\circ} \mathrm{C}$. After the tubes were brought to room temperature, $1 \mu \mathrm{L}$ of cysteine blocking reagent (200 mM methyl methanethiosulfonate in isopropanol) was added and incubated for $10 \mathrm{~min}$ at room temperature. Sequencing grade trypsin (Roche, Basel, Switzerland) was dissolved in $10 \mathrm{mM} \mathrm{HCL}$ at a concentration of $1 \mu \mathrm{g} / \mu \mathrm{L}$ prior to the addition of trypsin to each sample at a trypsin to protein ratio of 1:50 $(w / w)$. The samples were then incubated at $37^{\circ} \mathrm{C}$ for $16-18 \mathrm{~h}$.

Labeling with iTRAQ

After trypsin digestion, the labeling was performed using buffers and components for maximum compatibility with iTRAQ reagent chemistry per manufacturer's instructions. The iTRAQ reagents $(113-119,121)$, each prepared in $70 \mu \mathrm{L}$ ethanol, were added to each sample containing $50 \mu \mathrm{g}$ of protein as outlined in Table 1. The peptide-label mixtures were incubated for $1 \mathrm{~h}$ at room temperature. The eight iTRAQ reagent-labeled samples were then mixed in equal proportions into a single vial and dried in vacuo.

\section{Strong Cation Exchange Chromatography}

The pooled iTRAQ-labeled sample representing $400 \mu \mathrm{g}$ of total protein was reconstituted in $8 \mathrm{~mL}$ of mobile phase A

Table 1 Experimental design

\begin{tabular}{|c|c|c|c|}
\hline Label & Subject ID & Gender & Condition \\
\hline \multicolumn{4}{|l|}{ Set A } \\
\hline 113 & Pool of all samples & $\mathrm{M} / \mathrm{F}$ & $\mathrm{C} / \mathrm{D}$ \\
\hline 114 & 7839 & $\mathrm{~F}$ & $\mathrm{C}$ \\
\hline 115 & 7840 & $\mathrm{~F}$ & $\mathrm{C}$ \\
\hline 116 & 7841 & $\mathrm{~F}$ & $\mathrm{C}$ \\
\hline 117 & 7852 & $\mathrm{~F}$ & $\mathrm{C}$ \\
\hline 118 & 3822 & $\mathrm{~F}$ & $\mathrm{D}$ \\
\hline 119 & 3829 & $\mathrm{~F}$ & $\mathrm{D}$ \\
\hline 121 & 3830 & $\mathrm{~F}$ & $\mathrm{D}$ \\
\hline \multicolumn{4}{|l|}{ Set B } \\
\hline 113 & Pool of all samples & $\mathrm{M} / \mathrm{F}$ & $\mathrm{C} / \mathrm{D}$ \\
\hline 114 & 7856 & M & $\mathrm{C}$ \\
\hline 115 & 7857 & M & $\mathrm{C}$ \\
\hline 116 & 7860 & M & $\mathrm{C}$ \\
\hline 117 & 3735 & M & $\mathrm{D}$ \\
\hline 118 & 3786 & M & $\mathrm{D}$ \\
\hline 119 & 3812 & M & $\mathrm{D}$ \\
\hline 121 & 3833 & M & $\mathrm{D}$ \\
\hline
\end{tabular}


containing $10 \mathrm{mM} \mathrm{KH} \mathrm{KO}_{4}$ and $25 \% v / v$ ACN (pH 2.1). The 8-mL sample was loaded onto an Agilent 1100 with a polysulfoethyl aspartamide column $(5 \mu \mathrm{m}, 200 \AA$, 4.6× $100 \mathrm{~mm}$, Nest Group, Southborough, MA, USA) for separation. Peptides were eluted from the column at a flow rate of $1 \mathrm{~mL} / \mathrm{min}$ using a linear gradient of $0-100 \%$ mobile phase $\mathrm{B}$ for $11 \mathrm{~min}$. The composition of mobile phase $\mathrm{B}$ was $500 \mathrm{mM} \mathrm{KCl}, 10 \mathrm{mM} \mathrm{KH}_{2} \mathrm{PO}_{4}$, and 25\% v/v ACN (pH 2.1). Fractions were collected in $1 \mathrm{~min}$ increments, and fractions 1-12 were dried in vacuo.

\section{Reverse Phase Chromatography}

Each SCX fraction was reconstituted in buffer A $(2 \% v / v$ ACN, $0.1 \% v / v$ TFA). A $20 \%$ portion of the reconstituted sample in a final volume of $30 \mu \mathrm{L}$ was injected onto a Tempo LC ${ }^{\text {TM }}$ MALDI spotting system (ABI) for reverse phase chromatography. After injection, peptides were trapped onto a guard column $(\mathrm{C} 18,3 \mathrm{~mm}$, Dionex, Sunnyvale, CA, USA), washed with buffer A for $10 \mathrm{~min}$ at $20 \mu \mathrm{L} / \mathrm{min}$, and subsequently separated on an analytical column (PepMap C18, $3 \mu \mathrm{m}, 150 \times 0.1 \mathrm{~mm}$, Dionex). Peptides were separated using a 45 -min gradient from $2 \%$ to $35 \%$ buffer B $(85 \% v / v$ ACN, $5 \% v / v$ isopropanol, $0.1 \%$ $v / v$ TFA) at a flow rate of $500 \mathrm{~nL} / \mathrm{min}$. Column eluent was mixed with matrix $(7 \mathrm{mg} / \mathrm{mL} \quad \alpha$-cyano-4-hydoxycinnamic acid in $75 \% v / v$ ACN, $0.1 \% v / v$ TFA, $10 \mathrm{mM}$ ammonium phosphate, $10 \mathrm{fmol} / \mu \mathrm{L}$ internal calibrant Glu-Fibrinopeptide B) at $1.2 \mu \mathrm{L} / \mathrm{min}$ and spotted in $10 \mathrm{~s}$ intervals with a Probot Micro Fraction collector (Dionex) onto blank Opti-TOF MALDI target plates (ABI). A total of 240 spots were collected per LC run.

\section{Mass Spectrometric Analysis}

Peptide analysis was performed on a 4800 MALDI TOFTOF Analyzer (ABI) in a data-dependent fashion, where MS spectra were acquired in positive ion reflector mode over a mass range of $800-4,000 \mathrm{~m} / \mathrm{z}$ with 1,000 laser shots per spot. MS data were processed with internal calibration and filtered through the following criteria to determine a maximum of 20 precursors for MS/MS per spot: minimum signal/noise of 25 and fraction-to-fraction mass tolerance of $200 \mathrm{ppm}$. Tandem MS spectra were acquired with 2,500 laser shots and a 200 resolution (full width at half maximum) mass window per precursor. Fragmentation was induced with $2 \mathrm{kV}$ collision energy and air at 1.2 torr for the collision gas. MS/MS data were processed with default calibration.

\section{Database Search}

Protein identification was carried out using the Protein Pilot $^{\text {TM }}$ Software v2.0 (ABI). The Paragon algorithm in
Protein Pilot ${ }^{\mathrm{TM}}$ Software was used as the default search program [23]. Searches with trypsin as the digestion agent were allowed for iTRAQ labeling modifications to the Ntermini of peptides and the side chains of lysine and tyrosine residues and alkylation of cysteines by methanemethylthiosulfonate. The search also included the possibility of more than 80 biological modifications and allowed for semitryptic peptides. MS/MS data were searched against an International Protein Index human database (version 3.28). A concatenated target-decoy database search strategy was also employed to estimate the rate of false positives. Only proteins identified with at least $95 \%$ confidence, or a ProtScore of 1.3 were reported.

\section{Quantitation and Statistical Analysis}

The iTRAQ reporter ion abundances in MS/MS scans were also evaluated using Protein Pilot ${ }^{\mathrm{TM}}$ Software for relative quantitation of proteins. For each peptide used for protein identification, peak areas for peaks at $m / z 113-119$ and 121 were calculated. To correct for experimental errors, the median peptide ratio was calculated for all peptides reported, adjusted to unity and then the same bias factor was applied to all ratios (within ProteinPilot). This normalizing factor is based on the assumption that most of the protein levels in the CSF from AD should be similar to those from normal controls with the exception of those that are related to the disease. For proteins with two or more qualified peptide matches, seven average peak area ratios (designated as 121/113, 119/113, 118/113, 117/113, 116/ $113,115 / 113$, and $114 / 113$ ) were calculated using the peak area ratios of the peptides originating from the same protein. The standard deviation (SD), the percent coefficient of variation $(\mathrm{CV})$ for each average peak area ratio, and the average $\mathrm{CV}$ using the $\mathrm{CVs}$ for the average peak area ratios for each protein were calculated. MS/MS spectra without a complete set of eight measurable iTRAQ tags were excluded from the quantitation analysis.

The protein list from the two iTRAQ experiments were merged with ratios calculated to the global standard 113 . Data sets were imported into Expressionist (GeneData, Basel, Switzerland) for further analysis. The ratios were compared between the profiles corresponding to NDC and AD. Two-group statistics with Benjamini-Hochberg corrections for multiple testing, using $q$ values, was carried out by performing the nonparametric Wilcoxon signed-rank test on logarithmic transformed ratios to detect statistically significant protein changes between NDC and AD within the respective gender groups ( $p$ value $<0.05$ ). Two-way analysis of variation (ANOVA) was used on the merged data set to identify a disease effect in the presence of a disease and gender factor $(p$ value $<0.05)$. Principle component analysis (PCA) was performed to visualize the 
relative location of each individual sample in lowdimensional space, allowing for detection of outliers or other relevant patterns such as interindividual variation and group separation based on a selected set of variables.

\section{Results}

\section{Assessment of iTRAQ Ratios}

For biomarker discovery experiments, reliable and reproducible protein profiles must be obtained to ensure that the variation in relative protein expression ratios reflects biological differences rather than systematic variability. The isobaric nature of the tags permitted the simultaneous comparison of seven individual samples to a pooled standard. The multiplex nature of the experiment should, therefore, remove any technical variability from chromatography and mass spectrometry that may be seen in sequential two-dimensional LCMS analyses of individual peptide mixtures.

The individual ratio of identified peptides from each of the CSF samples compared to the control pool were computed from signature ion peak areas as described in methods and normalized using the overall ratios for all proteins to account for small differences in protein loading. For proteins with two or more qualified peptide matches, the $\mathrm{SD}$, the percentage $\mathrm{CV}$ for each average peak area ratio, and the average $\mathrm{CV}$ using the CVs for the seven average peak area ratios for each protein were calculated to demonstrate the accuracy of labeling. The average of the protein-level SD was 0.25 and 0.28 for data sets A and B, respectively. This equates to an average $\mathrm{CV}$ of $24 \%$ and $23 \%$, respectively, for data sets $\mathrm{A}$ and $\mathrm{B}$, and demonstrates a high degree of concordance between individual peptides contributing to the relative quantitation of any given protein.

In addition to reproducible ratio calculations, it is desirable to analyze data across multiple iTRAQ experiments since it allows studies to incorporate larger sample sizes, obtaining more accurate estimates of biological effects and thus having more statistical power to detect meaningful differences. In this study, the 8-plex experiments were divided into two sample sets based on gender. However, a common pooled sample was used for the reference 113 tag in both sample sets. This reference design would permit the assignment of ratios relative to a common sample (the denominator) and to quantify and correct for experimental variability across multiple 8-plex experiments. After merging the two separate 8-plex experimental results together into a single database, the SD and CV between individuals within and across gender were calculated from the average ratio of each protein across the different samples. A total of 300 proteins were quantified, and the calculated values are summarized in Table 2 .
Table 2 Comparison of coefficients of variance and standard deviation within and across groups

\begin{tabular}{lccc}
\hline Sample Set & Av. mean & Av. SD & Av. \%CV \\
\hline Female NDC & 1.029 & 0.2 & 18.6 \\
Female AD & 1.028 & 0.17 & 15.3 \\
Male NDC & 1.022 & 0.16 & 15.4 \\
Male AD & 1.05 & 0.22 & 18.7 \\
All & 1.02 & 0.21 & 20.4 \\
\hline
\end{tabular}

Average CVs ranging from $15 \%$ to $18 \%$ for relative protein expression ratios between individuals within gender were obtained. When all 14 individuals were compared, an average CV of $20.38 \%$ was observed. Overall, the CVs calculated within and across the two 8-plex experiments indicate that when using a common standard across multiple 8-plex experiments, the calculated average ratios for relative quantitation of protein levels is reliable and reproducible. This should enable strategies with statistically sound sample sizes to be used for biomarker discovery, in a timely and cost effective manner.

\section{Identification of CSF Proteins}

Protein identification was based on meeting the criteria of having one or more peptides with individual ProteinPilot scores above the $95 \%$ confidence threshold $(p<0.05)$ and ion score confidence interval values above $99 \%(p<0.01)$. Using these criteria, we were able to identify 408 and 379 proteins from iTRAQ data set A and B, respectively. ProteinPilot automatically only includes unique and high confidence matches of peptides in the ratios reported (i.e., it excludes those that are shared between different isoforms of any protein or low confidence matches to peptides). Among the proteins detected, 138 (data set A) and 154 (data set B) proteins were identified with one unique peptide with a minimum peptide confidence of $95 \%$, in the respective data sets. Using the concatenated target-decoy database search strategy, a less than $5 \%$ rate of false positives was estimated, which further strengthened the reliability of our data. The protein list from the two iTRAQ data sets were merged revealing a list of 300 common proteins, as well as $105(25.90 \%)$ and $87(22 \%)$ proteins unique to data set $\mathrm{A}$ and $\mathrm{B}$, respectively.

The CSF proteins identified were categorized according to their cellular functions and their cellular locations based on Ingenuity Pathway Analysis (Ingenuity Systems, Redwood City, CA, USA). Of the proteins identified, 39\% were assigned as extracellular, $24.5 \%$ as cytoplasmic, $24.5 \%$ as membrane associated, $6.7 \%$ as nucleus, and $4 \%$ as unknown. A significant portion of the identified proteins in CSF is related to CNS structure and function. At least $12 \%$ of the 
proteins identified in CSF were assigned as neuronal proteins, serving functions in signal transduction, neuronal development, axonal growth, or synaptic function. Moreover, $22 \%$ are implicated in neurological diseases. It is difficult to know just how many proteins are exclusively of neural origin because many proteins are likely expressed in other tissues and, therefore, could potentially be introduced into CSF from systemic circulation. Indeed, the other major class of proteins belongs to those that can be observed in plasma, including those related to acute phase response, immunity and coagulation. These data are, however, reassuring as they support our approach to identify a significant number of proteins related to CNS.

The concentration of protein in the CSF is only $0.2 \%$ to $0.5 \%$ that of blood. Subsequently, any minor contamination of CSF with blood during lumbar puncture may dramatically alter the protein profile confounding the identification of potential biomarkers. In this study, we identified the major CNS apolipoproteins known to be present in the CSF with matched peptides ranging from eight to 120 peptides for each protein. Apolipoprotein B, the major lipoprotein in blood that is absent or present in only very small amounts in CSF, was identified only in the female data set with five peptide matches. These data confirmed the absence or negligible degree of blood contamination present in the CSF samples.

\section{Statistically Significant Changes in the CSF Proteome Associated with AD}

For protein quantitation, peak areas for iTRAQ tag peaks $(113-119,121 \mathrm{~m} / \mathrm{z})$ were determined, and after normalization of sample quantities using median ratios, differential expression between NDC and AD was evaluated for combined and gender-specific data sets by performing univariate and multivariate analysis.

Nonparametric Wilcoxon signed-rank test $(p<0.05)$ was performed on logarithmic transformed ratios to detect quantitative protein changes between $\mathrm{NDC}$ and $\mathrm{AD}$ for gender-specific data sets. For each protein, a BenjaminiHochberg $q$ value was calculated to control for false positives as a consequence of multiple testing effects [24, 25]. A total of 20 and 51 proteins from the respective male and female data sets were detected as differentially expressed between $\mathrm{AD}$ and NDC within the selected $p$ value significance threshold. However, these differences were concomitantly associated with high false discovery rates ( $q$ values 0.7 and 0.4 , respectively, for male and female). In the case of the female data set, a $q$ value of 0.4 shows that about 20 of the 51 significant protein differences are false positives. This inability to detect significant changes with an acceptable ratio of true and false positives arises from a lack of statistical power.

In order to increase statistical power, both data sets were combined using only those proteins common to both. As the experiments were split between genders, a batch effect was expected which had to be taken onto consideration when analyzing the combined data for differential differences between NDC and AD groups. In order to control the batch effect and ensure that the disease effect on protein expression is not underestimated relative to the batch effect, we used a two-way ANOVA with on the 300 common proteins from the combined data set to identify a disease status in the presence of a disease status and gender factor setting [26]. A total of 24 proteins was found to change significantly with disease $(p<0.05)$ using two-way ANOVA. These proteins, all confidently identified with more than or equal to two peptide matches, are given in Table 3. Importantly, these differences were associated with a lower Benjamini-Hochberg $q$ value of 0.32 compared to with single data set experiments. PCA of the 24 proteins demonstrated a clear separation of gender and condition (Fig. 1).

\section{Identification of Possible Biomarker Candidates}

Table 4 lists the functional roles attributed to the regulated proteins identified from two-way ANOVA statistics. A significant portion of these proteins are of CNS origin and involved in processes such as signal transduction, neuronal development, axonal growth and synaptic function, immune response, and inflammation. Moreover, several of the proteins identified in this study have previously been reported by others to have altered protein levels in $\mathrm{AD}$ pathology and in other CNS disorders.

\section{Discussion}

The comprehensive study of human CSF proteome has become possible as highly sensitive mass spectrometry and labeling technologies have developed [19, 21, 22, 27, 28]. In this study, we examined the feasibility of applying a 2DLC-MALDI-MS/MS approach incorporating 8-plex iTRAQ labeling to quantify the CSF protein component. The principal aims were (1) to define the extent of protein coverage obtainable using this approach in terms of their biological roles and relevance to CNS and (2) to highlight potential biomarker candidates of $\mathrm{AD}$ for verification and validation studies.

Using a pooled reference sample in the experimental design allowed the assignment of ratios relative to the common denominator and to quantify and correct for experimental variability across multiple 8-plex experiments. Such a reference design has previously been acknowledged as imperative for biomarker discovery experiments that require comparative analyses from multiple iTRAQ experimental runs [26, 29]. Our results showed that the methodology afforded high quantitative reproducibility at the protein level. Even though technical replicates were not 
Table 3 Differentially expressed proteins between AD and NDC using two-way ANOVA $(p<0.05)$

\begin{tabular}{|c|c|c|c|c|c|}
\hline \multirow[t]{2}{*}{ Accession \# } & \multirow[t]{2}{*}{ Description } & \multirow[t]{2}{*}{$p$ value } & \multicolumn{2}{|c|}{$\begin{array}{l}\text { Fold } \\
\text { change }^{\mathrm{a}}\end{array}$} & \multirow[t]{2}{*}{ Modulation } \\
\hline & & & $\mathrm{F}$ & M & \\
\hline CH3L1_HUMAN (P36222) & Chitinase-3-like protein 1 & 0.0006 & 1.3 & 1.4 & Up \\
\hline GUAD_HUMAN (Q9Y2T3) & Guanine deaminase & 0.0025 & 1.8 & 1.2 & Up \\
\hline IGX1_HUMAN (Q8TAG5) & Semaphorin7A & 0.0058 & 1.2 & 1.2 & Up \\
\hline CO1A1_HUMAN (P02452) & Collagen alpha $1(\mathrm{I})$ chain & 0.0064 & 1.3 & 1.1 & Up \\
\hline SPTA2_HUMAN (Q13813) & Spectrin alpha chain, brain & 0.0102 & 1.5 & 1.6 & Down \\
\hline PROS_HUMAN (P07225) & Vitamin K-dependent protein $\mathrm{S}$ & 0.0134 & 1.1 & 1.2 & Down \\
\hline GGH_HUMAN (Q92820) & Gamma-glutamyl hydrolase precursor & 0.0148 & 1.2 & 1.2 & Up \\
\hline BASP_HUMAN (P80723) & BASP1 protein (NAP-22) & 0.0157 & 1.6 & 1.3 & Up \\
\hline CO1A2_HUMAN (P08123) & Collagen alpha 2(I) chain & 0.0167 & 1.2 & 1.2 & Up \\
\hline SPB6_HUMAN (P35237) & $\begin{array}{l}\text { Placental thrombin inhibitor } \\
\text { (cytoplasmic antiproteinase) }\end{array}$ & 0.0179 & 1.3 & 1.2 & Down \\
\hline NCA11_HUMAN (P13591) & N-CAM 140 & 0.0190 & 1.3 & 1.1 & Up \\
\hline LRP1_HUMAN (Q07954) & Low-density LRP1 & 0.0209 & 1.1 & 1.2 & Down \\
\hline TPIS_HUMAN (P60174) & Triosephosphate isomerase & 0.0216 & 1.6 & 1.2 & Up \\
\hline CSTN1_HUMAN (O94985) & Calsyntenin-1 & 0.0271 & 1.2 & 1.1 & Up \\
\hline SODC_HUMAN (P00441) & Superoxide dismutase & 0.0339 & 1.4 & 1.1 & Up \\
\hline MOG_HUMAN (Q16653) & Myelin-oligodendrocyte glycoprotein & 0.0342 & 1.2 & 1.3 & Up \\
\hline CAH11_HUMAN (O75493) & CARP-2 & 0.0347 & 1.3 & 2.0 & Up \\
\hline PGRP2_HUMAN (Q96PD5) & $\mathrm{N}$-Acetylmuramoyl-L-alanine amidase precursor & 0.0350 & 1.3 & 1.1 & Down \\
\hline 1433Z_HUMAN (P63104) & 14-3-3 protein zeta/delta (protein KCIP-1) & 0.0390 & 1.3 & 1.3 & Up \\
\hline OSTP_HUMAN (P10451) & Osteopontin & 0.0395 & 1.2 & 1.2 & Up \\
\hline NXPH1_HUMAN (P58417) & Neurexophilin-1 & 0.0409 & 1.1 & 1.3 & Down \\
\hline TETN_HUMAN (P05452) & TN precursor (plasminogen-kringle 4 binding protein) & 0.0448 & 1.1 & 1.1 & Up \\
\hline ASPG_HUMAN (P20933) & $\begin{array}{l}N(4) \text {-(beta- } N \text {-acetylglucosaminyl)- } \\
\text { L-asparaginase precursor (glycosylasparaginase) }\end{array}$ & 0.0488 & 1.2 & 1.2 & Up \\
\hline MDHC_HUMAN (P40925) & Malate dehydrogenase, cytoplasmic & 0.0494 & 1.2 & 1.1 & Up \\
\hline
\end{tabular}

$B A S P 1$ brain acid soluble protein 1, NAP-22 neuronal axonal membrane protein 22, LRP1 lipoprotein receptor-related protein $1, C A R P-2$ carbonic anhydrase-related protein $2, K C I P-1$ protein kinase $\mathrm{C}$ inhibitor protein $1, T N$ tetranectin precursor, $N-C A M 140$ neural cell adhesion molecule 1 , $140 \mathrm{kDa}$ isoform precursor

${ }^{\mathrm{a}}$ The magnitude of change in linear space; the greater of ratio or $1 /$ ratio of change

used, the combined run to run technical and biological variance across all 14 individual subjects was well within the acceptable range for analytical measurements (CV $20 \%$ ). This is in spite of the slightly higher variance observed between different peptides for a given protein.

In clinical biomarker research, the general workflow employed for the implementation of a clinical useful biomarker involves the discovery phase, the verification phase, and finally, the validation phase [30]. During the discovery phase, a small number (tens) of samples are analyzed using low sample throughput proteomic platforms for nonbiased semiquantitative profiling of as many proteins as possible in a biological matrix. Obviously, such studies are statistically underpowered resulting in the detection of a large number of differential proteins as potential candidate markers. However, in such comparative proteomic analysis, many hundreds of statistical tests are conducted, one for each feature (or protein), across a substantially smaller sample number, resulting in the accumulation of a considerable number of false positives [31]. The accumulation of false positives is termed the multiple testing problem and is a general property of a confidence-based statistical test when applied across multiple features for few samples. This is especially true for independent analyses of single iTRAQ experiments. We obtained unacceptably high false discovery rates ( $q$ values) among differentially expressed proteins assigned significant ( $p$ value 0.05 ) between $\mathrm{AD}$ and NDC within gender. These high false discovery rates arise from a lack of statistical power in a single iTRAQ experiment for the size of changes occurring and number of multiple testing that is performed. Increasing statistical power by the combination 


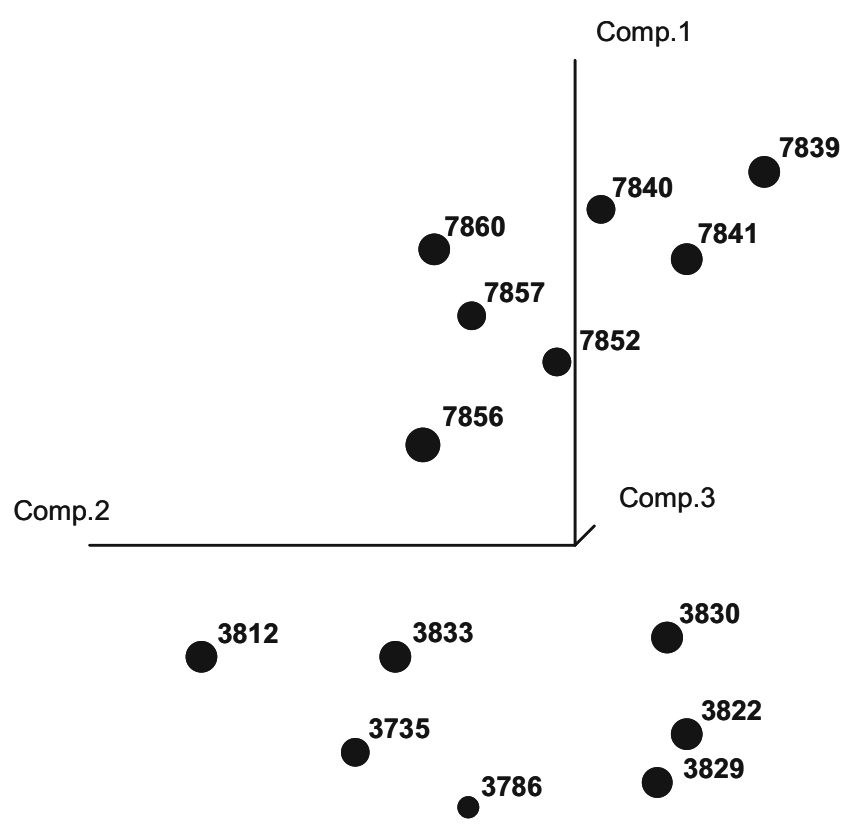

Fig. 1 Principle component analysis using the 24 proteins that were found to change significantly with disease $(p<0.05)$ following two-way ANOVA. The first, second, and third principle component axes are indicated. Each individual subject is recognized by their respective ID number, and the spatial relationship between the individuals is shown along the three axes. A gender-dependent separation is apparent along the first principle component, whereas a condition-dependent separation is apparent along the second principle component

of both iTRAQ experiments resulted in the assignment of significant ( $p$ value 0.05 ) protein differences between $\mathrm{AD}$ and NDC with improved $q$ values of 0.3 . In the case of biomarker discovery studies, this observation highlights the need to combine multiple 8-plex iTRAQ experiments to achieve a reasonable statistical power so as to reduce the rate of false positives and have a "cleaner" list of biomarker candidates for subsequent larger scale biomarker verification and validation phases.

Along with the demonstrated reproducibility of the approach, broad proteome coverage is necessary for discovering biomarker candidates in the CSF. Approximately 492 nonredundant proteins were confidently identified across the two iTRAQ experiments, 300 of which represented common proteins. A significant portion of the identified proteins were related to CNS structure and function, representing extracellular proteins, as well as known cytoplasmic, membraneassociated, and nuclear proteins involved in neuronal function and implicated in neurological diseases. Moreover, proteome coverage of the CSF could further be improved with more thorough immunodepletion and fractionation strategies. Thus, the broad spectrum of CNS-related proteins analyzed by this approach testifies to its potential as a sensitive tool for biomarker discovery.

ANOVA analysis identified a number of differences in the CSF level of proteins between AD and NDC. These included protein changes likely associated with neuronal loss, synaptic dysfunction, neuroinflammation, as well as neurodegenerative and tissue remodeling processes. In sporadic $\mathrm{AD}$, a neuroinflammatory process is thought to play a central role in neurodegeneration. This inflammatory process is driven by activated microglia, astrocytes, and the induction of proinflammatory cytokines, leading to both synaptic and neuronal damage and further exacerbation of inflammatory cell activation [32-35]. Among the differentially regulated proteins, we observed elevated levels of myelin-oligodendrocyte glycoprotein, osteopontin, semaphorin7A, chitinase-3-like protein 1 , tetranectin, collagen $\alpha 2$ (I) chain, and collagen $\alpha 1$ (I) chain in the CSF from AD individuals. These proteins are involved in neuroinflammatory, oxidative stress, and neurodegenerative or tissue remodeling/proproliferative processes in the brain. For instance, elevated levels of osteopontin have been observed in the CSF of patients with multiple sclerosis and Parkinson's disease [36]. Increased osteopontin levels in the hippocampus of $\mathrm{AD}$ brain, as well as a positive correlation between osteopontin immunocytochemical staining intensity and $\mathrm{A} \beta 42$ load, has been reported [37]. Interestingly, osteopontin is primarily localized to those neurons that are known to be vulnerable to AD-related neurite loss, degeneration, and death. An increase in CSF levels of osteopontin may implicate proinflammatory processes and neuronal damage in AD brains. Similarly, increased CSF levels of myelin-oligodendrocyte glycoprotein, which is abundantly expressed in CNS myelin, may also reflect neuronal damage. Chitinase-3-like protein 1 is a matrix protein thought to be elevated, in response to inflammatory cytokines, during the acute stages of inflammation [38]. Along with increased CSF levels of collagen $\alpha 2$ (I) chain and collagen $\alpha 1$ (I) chain, the observed changes in the CSF levels of chitinase-3-like protein 1 in $\mathrm{AD}$ individuals may be indicative of the presence of tissue remodeling and proproliferative processes in $\mathrm{AD}$ brains such as the formation of glial scar tissue. Oxidative stress is also involved in the etiology of sporadic $\mathrm{AD}$, and evidence suggests that the accumulation of $A \beta$ adds to the oxidative burden in $\mathrm{AD}$ brains $[39,40]$. Activation of the oxidative burst is one of the earliest biochemical events in microglial activation resulting in the release of superoxide and nitric oxide. Increases in the CSF levels of superoxide dismutase in AD probably reflect a neuroprotective response against oxidative stress as a result of microglia activation and support a role for oxidative stress in the neurodegeneration of $\mathrm{AD}$ [41].

In addition to neuronal loss and atrophy, disruption of neural function including defects in axon guidance and synaptic plasticity and shortened dendritic lengths are generally ascribed to AD neurons [42-46]. In this study, a number of proteins involved in various aspects of neural function and neuritic abnormalities were identified as 
Table 4 Functional roles attributed to proteins differentially expressed between AD and NDC

\begin{tabular}{|c|c|c|}
\hline Protein name & Modulation & Function \\
\hline Collagen $\alpha 1(\mathrm{I})$ chain & $\uparrow$ & Tissue remodeling processes \\
\hline $14-3-3$ zeta & $\uparrow$ & A potent inhibitor of protein kinase C. CSF marker of brain injury/neurodegeneration \\
\hline $\begin{array}{l}\text { Chitinase-3-like protein } 1 \\
\text { (YKL-40) }\end{array}$ & $\uparrow$ & $\begin{array}{l}\text { Matrix protein thought to be secreted during the acute stages of inflammation. } \\
\text { Possible serologic marker of neutrophil function at the site of acute tissue inflammation }\end{array}$ \\
\hline Superoxide dismutase & $\uparrow$ & Main defense against superoxide produced during the course of respiration in mitochondria. \\
\hline Osteopontin & $\uparrow$ & $\begin{array}{l}\text { Pro-adhesive, chemotactic, and cytokine-like properties. Involved in a number of physiologic } \\
\text { and pathologic events including angiogenesis, apoptosis, inflammation, oxidative stress, } \\
\text { remyelination, wound healing, bone remodeling, cell migration, and tumorigenesis }\end{array}$ \\
\hline Collagen $\alpha 2(I)$ chain & $\uparrow$ & Tissue remodeling processes \\
\hline Vitamin K-dependent protein S & $\downarrow$ & $\begin{array}{l}\text { Mainly synthesized in hepatocytes and endothelial cells, plays a critical role in the } \\
\text { anticoagulant activity of plasma }\end{array}$ \\
\hline Gamma-glutamyl hydrolase & & $\begin{array}{l}\text { Cysteine peptidase, catalyzes the hydrolysis of poly-gamma-glutamate derivatives } \\
\text { of folate cofactors }\end{array}$ \\
\hline Brain acid soluble protein 1 & $\uparrow$ & Growth and guidance of neuron axons \\
\hline Tetranectin & $\uparrow$ & $\begin{array}{l}\text { A glycoprotein thought to play a prominent role in tissue remodeling: role in the regulation } \\
\text { of proteolytic processes via its binding to plasminogen and indirect activation of plasminogen }\end{array}$ \\
\hline Semaphorin7A & $\uparrow$ & $\begin{array}{l}\text { Axon guidance factor that assist growing axons in finding appropriate targets and } \\
\text { forming synapses. Initiates T cell-mediated inflammatory responses }\end{array}$ \\
\hline Calsyntenin-1 & $\uparrow$ & $\begin{array}{l}\text { A proteolytically processed protein of the post synaptic membrane. Modulator of post } \\
\text { synaptic intracellular } \mathrm{Ca} 2+\text { by extracellular proteolysis }\end{array}$ \\
\hline Triosephosphate isomerase & $\uparrow$ & $\begin{array}{l}\text { Adjusts the rapid equilibrium between dihydroxyacetone phosphate and } \\
\text { glyceraldehyde-3-phosphate produced by aldolase in glycolysis }\end{array}$ \\
\hline $\begin{array}{l}\text { Myelin-oligodendrocyte } \\
\text { glycoprotein }\end{array}$ & $\uparrow$ & $\begin{array}{l}\text { Myelin-specific protein of the CNS. Autoantigen capable to produce a demyelinating } \\
\text { multiple sclerosis-like disease in experimental animals. Present in the major dense } \\
\text { line of CNS myelin suggesting a role in the compaction or stabilization of myelin }\end{array}$ \\
\hline $\begin{array}{l}\text { Low-density lipoprotein } \\
\text { receptor-related protein } 1\end{array}$ & $\downarrow$ & Regulates ApoE and cholesterol levels within the CNS \\
\hline Placental thrombin inhibitor & $\downarrow$ & Coagulation inhibitor \\
\hline $\begin{array}{l}N \text {-Acetylmuramoyl-L-alanine } \\
\text { amidase precursor }\end{array}$ & $\downarrow$ & $\begin{array}{l}\text { May play a scavenger role by digesting biologically active PGN into biologically } \\
\text { inactive fragments }\end{array}$ \\
\hline $\begin{array}{l}N(4)-(\text { beta- } N- \\
\text { acetylglucosaminyl)-L- } \\
\text { asparaginase }\end{array}$ & $\downarrow$ & Innate immunity \\
\hline $\begin{array}{l}\text { Carbonic anhydrase-related } \\
\text { protein } 2\end{array}$ & $\uparrow$ & $\begin{array}{l}\text { Abundant in the brain with moderate expression also present in spinal cord. } \\
\text { Novel binding protein for inositol 1,4,5-trisphosphate receptor type } 1 \text {, } \\
\text { modulates } \mathrm{Ca}(2+) \text { signaling }\end{array}$ \\
\hline Guanine deaminase & $\uparrow$ & Dentrite branching (synaptic transmission) \\
\hline Spectrin $\alpha$ chain & $\downarrow$ & Major component of neuronal cytoskeletal proteins \\
\hline N-CAM 140 & $\uparrow$ & Plays important roles in neural migration, synaptogenesis and CNS development \\
\hline Malate dehydrogenase & $\uparrow$ & $\begin{array}{l}\text { Enzyme in the citric acid cycle that catalyzes the conversion of malate into } \\
\text { oxaloacetate (using NAD+) and vice versa }\end{array}$ \\
\hline Neurexophilin-1 & $\downarrow$ & $\begin{array}{l}\text { Neurexophilins are secreted peptides that are processed proteolytically } \\
\text { and that bind extracellularly alpha-neurexins. Possible role in synaptic transmission }\end{array}$ \\
\hline
\end{tabular}

$N$-CAM 140 neural cell adhesion molecule 1, $140 \mathrm{kDa}$ isoform precursor, $P G N$ peptidoglycan

differentially regulated in the $\mathrm{AD}$ group. These changes included a decrease in the CSF levels of neurexophilin-1 and spectrin $\alpha$ chain and an increase in the levels of brain acid soluble protein 1 (BASP1), carbonic anhydrase-related protein 2 (CA11), semaphorin7A, calsyntenin-1, and guanine deaminase. Brain area-specific alterations in synaptic protein levels may contribute to neocortical synaptic dysfunction in AD [47]. For instance, BASP1 (also known as cytoskeleton-associated protein-23 and neuronal axonal membrane protein-22) is a signaling protein that accumulates mainly in the axon endings (growth cones and the presynaptic area of the synapses) and participates in neurite outgrowth and synaptic plasticity $[48,49]$. Calsyntenin-1 is a protein of the postsynaptic membrane acting as a modulator of postsynaptic $\mathrm{Ca} 2+[50]$. Other proteins which were elevated in $\mathrm{AD}$ included guanine

\section{淧 Humana Press}


deaminase which promotes microtubule polymerization resulting in increased dentrite branching [51], semaphorin7A which promotes axon growth, and CAII which is a novel inositolphosphate-3 receptor binding protein expressed in Purkinje cells of the cerebellum and is proposed to play a role in synaptic morphology and function [52]. In contrast, the synaptic scaffold protein, spectrin $\alpha$ chain, which is implicated in synaptic plasticity [53] was decreased. Increased CSF levels of BASP1, semaphorin7A, and guanine deaminase in AD patients may reflect aberrant nerve sprouting or neuroplastic-related events. Indeed, aberrant neuroplasticity is one aspect of $\mathrm{AD}$ neuropathology that may lead to degenerative and hypotrophic events culminating in memory dysfunction $[54,55]$. Alternatively, these changes may also reflect degeneration of axons or presynaptic terminals. For instance, elevated CSF levels of the metabolic proteins triosephosphate isomerase and malate dehydrogenase, as well as 14-3-3 zeta, were observed in the AD group and could be related to an increased release from dying neurons.

Cholesterol is an essential component of membranes and myelin sheathes and is crucial for synaptic integrity and neuronal functions [56]. Indeed, an association between brain cholesterol metabolism and the risk of $\mathrm{AD}$ has been proposed. In this study, we observed decreased CSF levels of low-density lipoprotein receptor-related protein 1 (LRP1) in the AD group. Interestingly, LRP1 expression has been shown to regulate apolipoprotein $\mathrm{E}$ and cholesterol levels within the CNS. Therefore, one could postulate that changes in CSF LRP1 levels in AD individuals may reflect perturbations in cholesterol and neuronal dysfunction. A recent study had proposed gamma-secretase cleavage of amyloid precursor protein to play a central role in regulating apolipoprotein $\mathrm{E}$ and cholesterol metabolism in the CNS via LRP1 [57].

\section{Conclusion}

In summary, we report the use of a 2DLC-MALDI-MS/MS approach incorporating 8-plex iTRAQ labeling to examine the differential expression of CSF proteins from $\mathrm{AD}$ and NDC. A number of proteins with a known relationship to AD pathology were identified. Provided that sound experimental designing that encompasses the appropriate application of statistical procedures is employed, iTRAQ appears to be an efficient and reliable approach to facilitate the discovery of candidate CSF biomarkers on a selected set of well-defined samples. CSF biomarkers may become invaluable in the near future for early and noninvasive diagnosis, or as improved surrogates of prognosis and treatment response. Verification of candidate protein biomarkers is a necessary step in moving from the initial discovery to possible application. To do this, we intend to apply a targeted MS-based approach in CSF collected from larger patient cohorts. Consequently, the design of prospective studies in which CSF samples are collected longitudinally are especially valuable for assessing the performance of such biomarker candidates, for example, in identifying incipient $\mathrm{AD}$ in MCI cases.

\section{References}

1. Heese K, Akatsu H. Alzheimer's disease - an interactive perspective. Curr Alzheimer Res. 2006;3(2):109-21.

2. Cummings JL, Doody R, Clark C. Disease-modifying therapies for Alzheimer disease: challenges to early intervention. Neurology. 2007;69(16):1622-34.

3. Blennow K. CSF biomarkers for Alzheimer's disease: use in early diagnosis and evaluation of drug treatment. Expert Rev Mol Diagn. 2005;5(5):661-72.

4. Frey HJ, Mattila KM, Korolainen MA, Pirttila T. Problems associated with biological markers of Alzheimer's disease. Neurochem Res. 2005;30(12):1501-10.

5. Galasko D. Biomarkers for Alzheimer's disease - clinical needs and application. J Alzheimers Dis. 2005;8(4):339-46.

6. Sizova D, Charbaut E, Delalande F, Poirier F, High AA, Parker F, et al. Proteomic analysis of brain tissue from an Alzheimer's disease mouse model by two-dimensional difference gel electrophoresis. Neurobiol Aging. 2007;28(3):357-70.

7. Butterfield DA, Boyd-Kimball D. Proteomics analysis in Alzheimer's disease: new insights into mechanisms of neurodegeneration. Int Rev Neurobiol. 2004;61:159-88.

8. Fountoulakis M, Kossida S. Proteomics-driven progress in neurodegeneration research. Electrophoresis. 2006;27(8):1556-73.

9. Johnson MD, Yu LR, Conrads TP, Kinoshita Y, Uo T, McBee JK, et al. The proteomics of neurodegeneration. Am J Pharmacogenomics. 2005;5(4):259-70.

10. Kim SI, Voshol H, van Oostrum J, Hastings TG, Cascio M, Glucksman MJ. Neuroproteomics: expression profiling of the brain's proteomes in health and disease. Neurochem Res. 2004;29 (6):1317-31.

11. Liao L, Cheng D, Wang J, Duong DM, Losik TG, Gearing M, et al. Proteomic characterization of postmortem amyloid plaques isolated by laser capture microdissection. J Biol Chem. 2004;279(35):37061-8.

12. Sultana R, Boyd-Kimball D, Cai J, Pierce WM, Klein JB, Merchant M, et al. Proteomics analysis of the Alzheimer's disease hippocampal proteome. J Alzheimers Dis. 2007;11(2):153-64.

13. Zhang J, Goodlett DR, Montine TJ. Proteomic biomarker discovery in cerebrospinal fluid for neurodegenerative diseases. J Alzheimers Dis. 2005;8(4):377-86.

14. De Jong D, Kremer BP, Olde Rikkert MG, Verbeek MM. Current state and future directions of neurochemical biomarkers for Alzheimer's disease. Clin Chem Lab Med. 2007;45(11):1421-34.

15. Lovestone S, Guntert A, Hye A, Lynham S, Thambisetty M, Ward M. Proteomics of Alzheimer's disease: understanding mechanisms and seeking biomarkers. Expert Rev Proteomics. 2007;4(2):227-38.

16. Bailey P. Biological markers in Alzheimer's disease. Can J Neurol Sci. 2007;34(Suppl 1):S72-6.

17. Blennow K. Cerebrospinal fluid protein biomarkers for Alzheimer's disease. NeuroRx. 2004;1(2):213-25.

18. Tannu NS, Hemby SE. Methods for proteomics in neuroscience. Prog Brain Res. 2006;158:41-82.

19. Zhang J, Goodlett DR, Peskind ER, Quinn JF, Zhou Y, Wang Q, et al. Quantitative proteomic analysis of age-related changes in human cerebrospinal fluid. Neurobiol Aging. 2005;26(2):207-27. 
20. Keshishian H, Addona T, Burgess M, Kuhn E, Carr SA. Quantitative, multiplexed assays for low abundance proteins in plasma by targeted mass spectrometry and stable isotope dilution. Mol Cell Proteomics. 2007;6(12):2212-29.

21. Choe L, D'Ascenzo M, Relkin NR, Pappin D, Ross P, Williamson B, et al. 8-plex quantitation of changes in cerebrospinal fluid protein expression in subjects undergoing intravenous immunoglobulin treatment for Alzheimer's disease. Proteomics. 2007;7(20):3651-60.

22. Ogata Y, Charlesworth MC, Higgins L, Keegan BM, Vernino S, Muddiman DC. Differential protein expression in male and female human lumbar cerebrospinal fluid using iTRAQ reagents after abundant protein depletion. Proteomics. 2007;7(20):3726-34.

23. Shilov IV, Seymour SL, Patel AA, Loboda A, Tang WH, Keating SP, et al. The Paragon algorithm, a next generation search engine that uses sequence temperature values and feature probabilities to identify peptides from tandem mass spectra. Mol Cell Proteomics. 2007;6(9):1638-55.

24. Devlin B, Roeder K, Wasserman L. False discovery or missed discovery? Heredity. 2003;91(6):537-8.

25. Storey JD, Tibshirani R. Statistical significance for genomewide studies. Proc Natl Acad Sci U S A. 2003;100(16):9440-5.

26. Oberg AL, Mahoney DW, Eckel-Passow JE, Malone CJ, Wolfinger RD, Hill EG, et al. Statistical analysis of relative labeled mass spectrometry data from complex samples using ANOVA. J Proteome Res. 2008;7(1):225-33.

27. Ramstrom M, Ivonin I, Johansson A, Askmark H, Markides KE, Zubarev $\mathrm{R}$, et al. Cerebrospinal fluid protein patterns in neurodegenerative disease revealed by liquid chromatographyFourier transform ion cyclotron resonance mass spectrometry. Proteomics. 2004;4(12):4010-8.

28. Abdi F, Quinn JF, Jankovic J, McIntosh M, Leverenz JB, Peskind $\mathrm{E}$, et al. Detection of biomarkers with a multiplex quantitative proteomic platform in cerebrospinal fluid of patients with neurodegenerative disorders. J Alzheimers Dis. 2006;9(3):293-348.

29. Song X, Bandow J, Sherman J, Baker JD, Brown PW, McDowell MT, et al. iTRAQ experimental design for plasma biomarker discovery. J Proteome Res. 2008;7(7):2952-8.

30. Rifai N, Gillette MA, Carr SA. Protein biomarker discovery and validation: the long and uncertain path to clinical utility. Nat Biotechnol. 2006;24(8):971-83.

31. Karp NA, McCormick PS, Russell MR, Lilley KS. Experimental and statistical considerations to avoid false conclusions in proteomics studies using differential in-gel electrophoresis. Mol Cell Proteomics. 2007;6(8):1354-64.

32. Heneka MT, O'Banion MK. Inflammatory processes in Alzheimer's disease. J Neuroimmunol. 2007;184(1-2):69-91.

33. Ringheim GE, Szczepanik AM. Brain inflammation, cholesterol, and glutamate as interconnected participants in the pathology of Alzheimer's disease. Curr Pharm Des. 2006;12(6):719-38.

34. Rosenberg PB. Clinical aspects of inflammation in Alzheimer's disease. Int Rev Psychiatry. 2005;17(6):503-14.

35. von Bernhardi R, Eugenín J. Microglial reactivity to beta-amyloid is modulated by astrocytes and proinflammatory factors. Brain Res. 2004;1025(1-2):186-93.

36. Maetzler W, Berg D, Schalamberidze N, Melms A, Schott K, Mueller JC, et al. Osteopontin is elevated in Parkinson's disease and its absence leads to reduced neurodegeneration in the MPTP model. Neurobiol Dis. 2007;25(3):473-82.

37. Wung JK, Perry G, Kowalski A, Harris PL, Bishop GM, Trivedi MA, et al. Increased expression of the remodeling- and tumorigenicassociated factor osteopontin in pyramidal neurons of the Alzheimer's disease brain. Curr Alzheimer Res. 2007;4(1):67-72.
38. Recklies $\mathrm{AD}$, Ling $\mathrm{H}$, White $\mathrm{C}$, Bernier SM. Inflammatory cytokines induce production of CHI3L1 by articular chondrocytes. J Biol Chem. 2005;280(50):41213-21.

39. Butterfield DA, Perluigi M, Sultana R. Oxidative stress in Alzheimer's disease brain: new insights from redox proteomics. Eur J Pharmacol. 2006;545(1):39-50.

40. Chauhan V, Chauhan A. Oxidative stress in Alzheimer's disease. Pathophysiology. 2006;13(3):195-208.

41. Bayer TA, Schafer S, Breyhan H, Wirths O, Treiber C, Multhaup G. A vicious circle: role of oxidative stress, intraneuronal Abeta and $\mathrm{Cu}$ in Alzheimer's disease. Clin Neuropathol. 2006;25(4):163-71.

42. Stokin GB, Goldstein LS. Axonal transport and Alzheimer's disease. Annu Rev Biochem. 2006;75:607-27.

43. Li JZ, Vawter MP, Walsh DM, Tomita H, Evans SJ, Choudary PV, et al. Systematic changes in gene expression in postmortem human brains associated with tissue $\mathrm{pH}$ and terminal medical conditions. Hum Mol Genet. 2004;13(6):609-16.

44. Lacor PN, Buniel MC, Chang L, Fernandez SJ, Gong Y, Viola KL, et al. Synaptic targeting by Alzheimer's-related amyloid beta oligomers. J Neurosci. 2004;24(45):10191-200.

45. Lacor PN, Buniel MC, Furlow PW, Clemente AS, Velasco PT, Wood $\mathrm{M}$, et al. Abeta oligomer-induced aberrations in synapse composition, shape, and density provide a molecular basis for loss of connectivity in Alzheimer's disease. J Neurosci. 2007;27 (4):796-807.

46. Arendt T. Alzheimer's disease as a disorder of dynamic brain selforganization. Prog Brain Res. 2005;147:355-78.

47. Reddy PH, Mani G, Park BS, Jacques J, Murdoch G, Whetsell W $\mathrm{Jr}$, et al. Differential loss of synaptic proteins in Alzheimer's disease: implications for synaptic dysfunction. J Alzheimers Dis. 2005;7(2):103-17.

48. Korshunova I, Novitskaya V, Kiryushko D, Pedersen N, Kolkova K, Kropotova E, et al. GAP-43 regulates NCAM-180-mediated neurite outgrowth. J Neurochem. 2007;100(6):1599-612.

49. Mosevitsky MI. Nerve ending "signal" proteins GAP-43, MARCKS, and BASP1. Int Rev Cytol. 2005;245:245-325.

50. Cheng XR, Zhou WX, Zhang YX. The family of calsyntenins: learning and memory related genes. Sheng Li Ke Xue Jin Zhan. 2006;37(3):205-10.

51. Akum BF, Chen M, Gunderson SI, Riefler GM, Scerri-Hansen MM, Firestein BL. Cypin regulates dendrite patterning in hippocampal neurons by promoting microtubule assembly. Nat Neurosci. 2004;7(2):145-52.

52. Hirota J, Ando H, Hamada K, Mikoshiba K. Carbonic anhydraserelated protein is a novel binding protein for inositol 1, 4, 5trisphosphate receptor type 1. Biochem J. 2003;372(Pt 2):435-41.

53. Aloy EM, Weinmann O, Pot C, Kasper H, Dodd DA, Rulicke T, et al. Synaptic destabilization by neuronal Nogo-A. Brain Cell Biol. 2006;35(2-3):137-56.

54. Holahan MR, Honegger KS, Tabatadze N, Routtenberg A. GAP43 gene expression regulates information storage. Learn Mem. 2007;14(6):407-15.

55. Phinney AL, Deller T, Stalder M, Calhoun ME, Frotscher M, Sommer B, et al. Cerebral amyloid induces aberrant axonal sprouting and ectopic terminal formation in amyloid precursor protein transgenic mice. J Neurosci. 1999;19(19):8552-9.

56. Pfrieger FW. Role of cholesterol in synapse formation and function. Biochim Biophys Acta. 2003;1610(2):271-80.

57. Liu Q, Zerbinatti CV, Zhang J, Hoe HS, Wang B, Cole SL, et al. Amyloid precursor protein regulates brain apolipoprotein $\mathrm{E}$ and cholesterol metabolism through lipoprotein receptor LRP1. Neuron. 2007;56(1):66-78. 